\title{
Economic operation modeling and optimization of an island micro grid considering load control
}

\author{
Shu Liu ${ }^{1}$, Jian Zhou ${ }^{1}$, Hongli He ${ }^{2}$ a , Shuqing Zhao ${ }^{2}$ and Xiu Yang ${ }^{2}$ \\ ${ }^{1}$ Electric Power Research Institute, Shanghai municipal electric power company. No.117, Handan Road, Shanghai. \\ 200437, China \\ ${ }^{2}$ School of Electric Power Engineering, Shanghai University of Electric Power, No.2588, Changyang Road, Shanghai, \\ 200090, China
}

\begin{abstract}
This paper proposes a load control of island economy operation model. It coordinates the storage operation with diesel generator output, so as to achieve the economic operation purpose of power grid. In this paper, the micro network economic operation model is transformed into mixed integer programming problem, which is solved by the mature commercial software, and the new model is proved to be economical.
\end{abstract}

Keywords: economic operation; direct load control; battery life loss cost; micro grid.

\section{Introduction}

With the increasing demand of power supply side, the fossil energy is depleted. The energy supply and efficient use of the power industry have become a prominent problem in the power industry in various countries. In order to solve this problem, many countries have developed renewable energy. Micro grid [1 3], as a new distributed energy organization, has the characteristics of effective utilization and flexible control of renewable energy. Domestic and foreign scholars have carried out a lot of researches.

The operation mode of micro grid is different from traditional power grid because of grid-connected mode and islanded operation mode: grid-connected mode can use micro source output and large grid side absorption power to meet the load demand; islanded operation mode needs to control micro source and storage energy system effectively, so as to maintain the stable operation of the system.

Due to the geographical factors and other issues, there is still a large number of island micro grid which is powered by diesel engine in the remote areas such as islands, mountain villages and so on. In order to solve island economic operation problem, this paper proposes a new model.

\section{Micro grid operation model}

This paper studies the micro grid system structure including wind power, photovoltaic, diesel generator, battery storage system and load. When the micro grid is in stable operation state, the circuit

a Corresponding author : hehongli_2006@qq.com

(C) 2016. The authors - Published by Atlantis Press 598 
breaker is disconnected at the PCC point, and the micro source can provide power to the load through the converter.

\subsection{Wind power generation model}

Wind power generation is a widely used mature distributed generation technology. Fan output PWT is closely related to the actual wind speed V: when the actual wind speed is less than cut-in wind speed, the wind machine will stay in the outage state, the unit would not put into work. When the wind speed is higher than the cut-in wind speed, the wind machine will start to work. At this time, wind machine capture maximum wind energy to improve the wind energy utilization rate; when the wind speed is higher than the rated wind speed and lower than the cut-out wind speed, pitch-controlled system will start to work, reduce wind energy utilization coefficient. The machine will output rated power; when the wind speed is higher than the cut-out wind speed, for the protection of the fan, the unit output falls to zero.

Wind turbine output $\mathrm{P}_{\mathrm{WT}}$ and wind speed $\mathrm{V}$ have the following relationship:

$$
P_{W T}= \begin{cases}0, & v_{\text {in }}>v, v_{\text {out }} \leq v \\ P_{W, \tau} \frac{v^{3}-v_{\text {in }}^{3}}{v_{\tau}^{3}-v_{\text {in }}^{3}}, & v_{\text {in }} \leq v \leq v_{\tau} \\ P_{W, \tau} & v_{\tau} \leq v \leq v_{\text {out }}\end{cases}
$$

Where:

$P_{W, \tau}$-fan rated output;

$v$-actual wind speed;

$v_{\tau}$-rated wind speed;

$v_{\text {in }}$-cut-in wind speed;

$v_{\text {out }}$-cut-out wind speed.

Fan output uncertainty due to random variation of wind speed, a large number of statistical data show that average wind speed probability density consistent with the Weibull distribution [4].

$$
f(v)=\frac{k}{C}\left(\frac{v}{C}\right)^{k-1} e^{-\left(\frac{v}{c}\right)^{k}}
$$

Where:

c -scale coefficient of average wind speed in a certain period of time;

$\mathrm{k}$-describe the shape factor of the shape of the wind velocity distribution density function, usually take 1.8 2.8.

\subsection{Photovoltaic power generation model}

Photovoltaic power generation system is safe and environmentally friendly, and the installation is simple and flexible. A large number of statistical data shows that the output power of photovoltaic system is closely related to the intensity of light. The sun light intensity approximately obey the Beta distribution during $\mathrm{t}$ time period, the probability density function is as follows:

$$
f(s)=\frac{\Gamma(\delta+\varphi)}{\Gamma(\delta) \Gamma(\varphi)}\left(\frac{s}{s_{\max }}\right)^{\delta-1}\left(1-\frac{s}{s_{\max }}\right)^{\varphi-1}
$$

Where:

$s$-actual light intensity in this time period; 
$S_{\max }$-maximum light intensity in this time period;

$\delta$-shape parameter of Beta distribution;

$\psi$-shape parameter of Beta distribution, $\psi=\delta(1-\mu) / \mu$;

$\mu$-average light intensity.

The output power of photovoltaic cell array can be simplified as:

$$
P_{P V}=\xi \eta_{m} A_{p v} \eta_{p} \cos \theta
$$

Where:

$\xi$-light radiation;

$\theta$-light incidence angle;

$\eta_{\mathrm{m}}$-MPPT efficiency;

$A_{p v}$-total area of photovoltaic cell panel;

$\eta_{P}$-photoelectric conversion efficiency of photovoltaic cells.

\subsection{Diesel generator model}

The operation cost of the diesel generator is similar to that of the fuel cost of the fossil fired power unit, which is the quadratic function of the output power, and the specific parameters can be provided by the manufacturer.

$$
C=a+b \underset{D G}{ }(t)+c P_{D G}^{2}(t)
$$

Where:

$a, b, c$-operating cost coefficient of diesel generator;

$P_{D G}$-diesel generator output power.

\subsection{Battery life loss cost model}

The life loss of the battery is mainly related to the charge and discharge cycle number [5]. The equivalent economic cost of the corresponding charge and discharge cycle is expressed as follows:

$$
C_{1}=\frac{C_{\text {invest }}}{N_{S B}}
$$

Where:

$C_{\text {invest }}$-battery investment cost;

$N_{S B}$-times of maximum cycle charge and discharge of battery;

In a complete scheduling cycle, the life loss cost of the battery is expressed as follows:

$$
C_{S B}=N_{s w} \cdot C_{l}
$$

Where:

$N_{s w}$-cycle times of battery charging and discharging in scheduling cycle.

\section{Direct load control model}

Nowadays Load Control Direct (DLC), as a simple and feasible load control method, has been gradually improved and matured in foreign countries, and has been highly valued by the domestic power dispatch agencies. Direct load control aimed at the load which does not have a significant impact on the user's load when the supply is interrupted. Thus the load is usually cold and heat storage 
device, such as air conditioning, water heater etc. Statistics show that nearly $50 \%$ in the summer peak period of the typical daily load is air conditioning load. This paper selects the air conditioning load of the micro grid as a control object, by optimizing the load side with the power generation side arrangement, so as to achieve economic operation effect.

There are a lot of abroad researches about DLC. Document [6] provides a DLC model, whose operation and implementation is simple and low difficulty. But the model is not completely general scheduling of control periods. In this paper, the load control conditions are introduced into the island operation model of the micro grid, and the constraint conditions of model are transformed into linear conditions.

The single period control strategy only breaks the half maximum interrupt time. After the end of the load interruption, the power of the system can be connected. The interrupted load will be restored try to rebound to the original load level, thereby forming a rebound load. During direct load control period, the load contains three parts: the initial load, the interrupt load, and compensation amount of each interrupt. Two kinds of load control strategy are shown in Table 1, with $15 \mathrm{mins}$ for a period of time, the maximum air conditioning interruption time is 12 periods. The single period control strategy as an example, part of the power is interrupted by 6 periods sometime. After three compensation period, the interruptible load consumption will rebound by 222.

Table.1 DLC strategy

\begin{tabular}{cccc}
\hline Strategy & Interrupt period & Compensation & Period of compensation \\
\hline single period control & 6 & 222 & 3 \\
\hline
\end{tabular}

\section{Micro grid operation optimization model}

\subsection{Objective function}

In order to minimize the system operation cost, operation cost of the system includes micro operation cost $C t O P$, micro source start and stop cost $C t U C$, battery storage life loss cost $C_{S B}$, and direct load control compensation cost $C_{d l c}$, the objective function is expressed as follows:

$$
\begin{gathered}
\min F=\min \left\{\sum_{t=1}^{T}\left\{C_{O P}^{t}+C_{U C}^{t}\right\}+C_{S B}+C_{d l c}\right\} \\
C_{O P}^{t}=\sum_{i=1}^{N_{G}}\left(U_{i}^{t} C_{i}\left(P_{i}^{t}\right)\right) \\
C_{i}\left(P_{i}^{t}\right)=a_{i}\left(P_{i}^{t}\right)^{2}+b_{i} P_{i}^{t}+C_{i} \\
C_{U C}^{t}=S_{i}\left(1-U_{i}^{t-1}\right) U_{i}^{t}
\end{gathered}
$$

Where:

$T$-scheduling cycle;

$N_{G}$-number of micro source;

$U t i$-the state variable of the micro source $\mathrm{i}$ in the $\mathrm{T}$ period, $U t i=1$ means that the micro source start, $U t i=0$ means that the micro source shut down

$C_{i}$ (Pt i) -operation cost of micro source i in t period;

Pt $i$-active power of micro source i in t period;

$S_{i}$-micro source i start-up costs;

$C_{d l c}$-direct load control compensation costs; the cost of compensation is proportional to the 
amount of electricity, according to reference [7].

\subsection{Constraint conditions}

\subsubsection{System power balance constraint}

$$
\sum_{i=1}^{N_{G}} P_{i}^{t}+P_{d i s}^{t}-P_{c h a}^{t}=P_{d l c}^{t}
$$

Where:

Pt dis -energy storage discharge power in t period;

Pt cha-energy storage charge power in t period;

Pt dlc-full time control of the load.

\subsubsection{Micro source operating constraints}

$$
\begin{gathered}
P_{i, \text { min }} \leq P_{i}^{t} \leq P_{i, \max } \\
P_{i}^{t}-P_{i}^{t-1} \leq r_{u i} T_{1} \\
P_{i}^{t-1}-P_{i}^{t} \leq r_{d i} T_{1} \\
T_{i, \text { on }} \geq T_{i, M U} \\
T_{i, \text { off }} \geq T_{i, M D}
\end{gathered}
$$

Equation (15) stands for limit of the micro source output; equation (16-17) stand for micro source output climbing constraint; equation (18-19) stand for micro source minimum operating time and minimum shutdown time constraint.

Where:

$r_{u i}, r_{d i}$-the upward and downward climbing power of diesel generator I, $T_{1}$ refers to $1 \mathrm{~h}$;

$T_{i, o n}, T_{i, o f f}$-diesel generator i continuous operation time and continuous shutdown time;

$T_{i, M U}, T_{i, M D}$-minimum running time and minimum down time of diesel generator $\mathrm{i}$.

\subsubsection{Battery energy storage operation constraint}

Battery storage for the charging and discharging power has certain limitation, because battery charge or over discharge will shorten the service life of energy storage. There are many constraints as follows:

Battery charging and discharging power constraint:

$$
\begin{aligned}
& 0 \leq P_{\text {dis }}^{t} \leq P_{\text {dismax }} \\
& 0 \leq P_{\text {cha }}^{t} \leq P_{\text {chamax }}
\end{aligned}
$$

Battery power constraint:

$$
E^{t}=E^{t-1}+P_{c h a}^{t} \eta_{c h a}-P_{d i s}^{t} / \eta_{d i s}
$$




$$
E_{c a p} S O C_{\min } \leq E^{t} \leq E_{c a p} S O C_{\max }
$$

The battery cycle constraint:

$$
E^{0}=E^{T}
$$

Where:

$E_{\text {cap }}$-capacity of storage battery;

$S O C_{\min }$-minimum state of charge;

$S O C_{\max }$-maximum state of charge;

$\eta_{\text {cha }}, \eta_{\text {dis }}$-efficiency of charge and discharge of energy storage.

When put direct load control into the load, the controllable load will be subject to equality and inequality constraints [7].

\subsubsection{Equality constraints}

$$
P_{d l c}^{t}=P_{0}^{t}-\sum_{i=a_{0}}^{t} b c_{t+1-i} X^{t}+\sum_{i=a_{1}}^{a_{2}} b P_{t-d+1-i} X^{t}
$$

Where:

Pt dlc -load under single period control;

Pt 0 -original load;

$b$-the power of each interrupt load;

$X^{t}$-number of interrupted load groups at the beginning of the t period;

$P_{n}$-adopted compensation strategy, the full time control strategy compensates according to the "222" ratio of electricity: $P_{1}=2, P_{2}=2, P_{3}=2$;

$N$-total length of controlled period;

$a_{0}=\max \{1, t-d+1\} ; \quad a_{1}=\max \{1, t-d-w+1\} ; a_{2}=t-d ;$

$d$-interruption period;

$w$-interruption load corresponding to the compensation period.

\subsubsection{Inequality constraints}

Daily interruption of load power does not exceed the maximum controllable load power:

$$
\sum_{i=1}^{N} b X^{t} \leq m
$$

Where:

$m$-the total power of the controllable load.

\section{Example analysis}

The model can be transformed into mixed integer programming problem, which is solved by the mature commercial software GAMS. Therefore, this paper proposes an independent micro grid as an example to verify the strategy. The micro grid renewable source includes wind power and photovoltaic; controllable micro sources are two diesel generators for $60 \mathrm{~kW}$ and $100 \mathrm{~kW}$, the specific parameters are shown in Table 4, battery capacity is $120 \mathrm{kwh}$, the maximum charging power is $40 \mathrm{~kW}$. The maximum discharge power is $40 \mathrm{~kW}$, state of charge SOC is in the range of $[0.2,0.9]$, the load 
data comes from the summer typical day load. The controllable load is mainly for air conditioning load, the maximum controllable power is $40 \mathrm{kw}$. Figure 3 shows the solar wind power output curve. The single period load control puts into effect in the 52 periods during the peak load period.

Table 2. Operating parameters of micro source

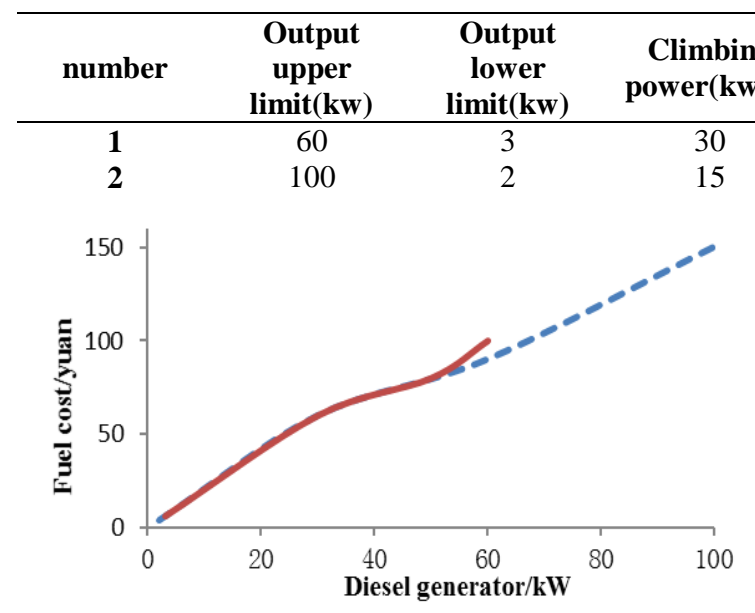

-0 100kW Diesel generator $\longrightarrow 60 \mathrm{~kW}$ Diesel generator

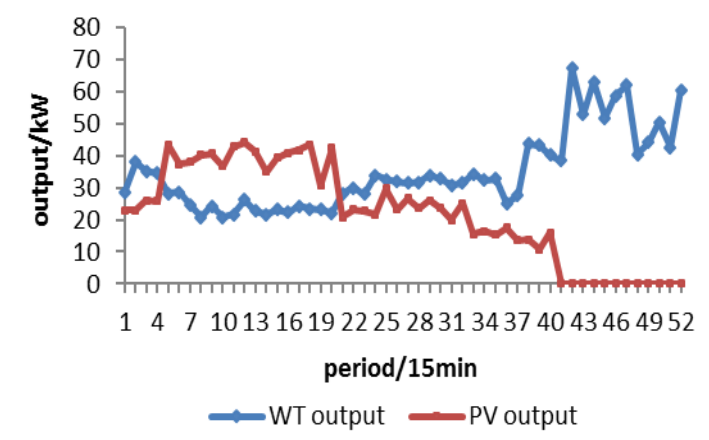

Figure 2. Wind power PV output curve

Figure 1. Diesel generator fuel cost curve

\begin{tabular}{cc}
$\begin{array}{c}\text { Down } \\
\text { climbing } \\
\text { power(kw/h) }\end{array}$ & $\begin{array}{c}\text { Start-up } \\
\text { cost(yuan) }\end{array}$ \\
\hline 20 & 2 \\
10 & 3
\end{tabular}

In view of the basic data, this paper makes two kinds of micro grid operation plan, such as Table 3. The first scheme adopts load control strategy, and each scheme is able to account for the life loss cost of the energy storage device. After the load control strategy is implemented on the load side, the original load is generated as the Figure 4.

Table 3. Comparison of three kinds of operation schemes

\begin{tabular}{ccccccc}
\hline number & strategy & $\begin{array}{c}\text { Total cost } \\
\text { (yuan) }\end{array}$ & $\begin{array}{c}\text { Operation } \\
\text { cost } \\
\text { (yuan) }\end{array}$ & $\begin{array}{c}\text { Compensation } \\
\text { cost(yuan) }\end{array}$ & $\begin{array}{c}\text { Energy } \\
\text { storage } \\
\text { cost } \\
\text { (yuan) }\end{array}$ & $\begin{array}{c}\text { Start-up } \\
\text { and } \\
\text { shutdown } \\
\text { costs(yuan) }\end{array}$ \\
\hline $\mathbf{1}$ & $\begin{array}{c}\text { single } \\
\text { period } \\
\text { control } \\
\text { non }\end{array}$ & 1365 & 1203 & 60 & 100 & 2 \\
$\mathbf{2}$ & 1471 & 1219 & 0 & 250 & 2 \\
\hline
\end{tabular}

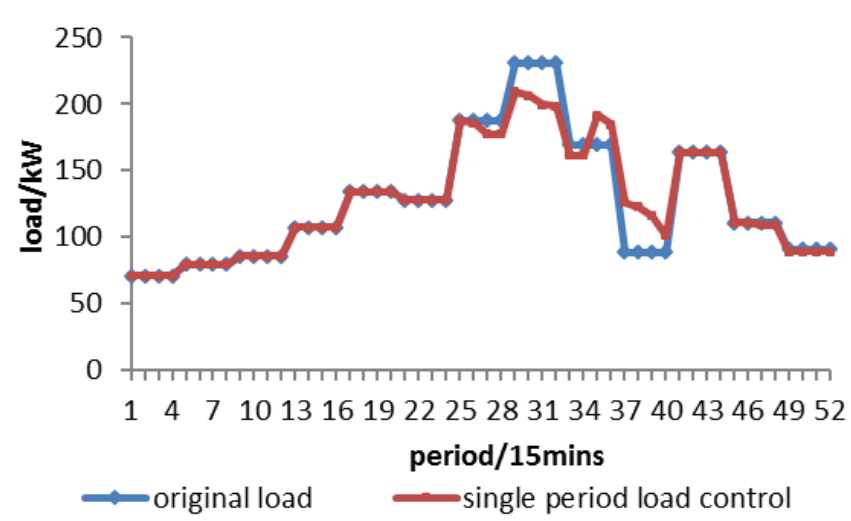

Figure 3. Single period control load curve 
It can be seen from Table 4, due to the introduction of load control strategy, the first schemes reduce the original load, so the economy is better. Compared with the two schemes, although fuel running cost growth is not big, but due to rely solely on the stabilization the system power fluctuations by storage battery, energy storage device charge and discharge frequently, resulting in storage life loss cost higher and total cost higher; after using the control strategy of single period, peak load reduced to $39.4 \mathrm{~kW}$. Therefore, the economic benefit of single period time control strategy is better.

\section{Conclusions}

This paper proposes an economic operation model of the independent micro grid. Model considers diesel generator operating costs, the cost of starting and stopping, storage life loss cost and load compensation costs. This paper applies demand response of direct load control measures to micro grid operation, so as to achieve better economy effect, and draws the following conclusions:

(1) The model introduces demand side load control strategy of micro grid optimization to help reducing the economic cost of micro grid.

(2) Compared with two kinds of load control strategy, it concludes that single period control strategy is better than non-control strategy in the economic cost and load shaping effect, so as to provide positive suggestions to implement demand response measures.

(3) The load control strategy can reduce the charge and discharge times of energy storage devices, and extend the service life of the energy storage device to a certain extent.

\section{Acknowledgment}

Projected Supported by State network Shanghai Municipal Electric Power Company science and technology projects (52094014001Z); Projected Supported by National Power Grid Corp science and technology project(520940150010).

\section{References}

1. KATIRAEL, IRAVANI R, HATZIARGYRIOUN, et al. Microgrids Management [J]. IEEE Power and Energy Magazine, 6(3):54-56(2008)

2. Hatziargyriou N, Asand H, Iravani, et al. Microgrids [J]. IEEE Power and Energy Magazine, 5(4):78-94(2007)

3. Piagi P, Lasseter R H. Control and design of microgrid components[R]. USA: Power Systems Engineering Research Center, (2006).

4. Karki R, Hu P, Billinton R.A simplified wind power generation model for reliability evaluation [J]. IEEE Transactions on Energy Conversion, 21(2):533-540(2006)

5. Sun Hao, Zhang lei, etc. Mixed integer programming model for micro-grid intra day scheduling [J]. Automation of Electric Power Systems. 2015(19)

6. Kurucz C N, Brandt D, Sim S. A linear programming model for reducing system peak through customer load control programs [J]. IEEE Transactions on Power Systems, 11(4): 1817-1824(1996)

7. Zhu Lan, Yan Zheng etc. Integrated resources planning in micro-grid based on modeling demand response [J]. Proceedings of the Chinese Society for Electrical Engineering, 2014(16):2621-2628 